\title{
Cor Triloculare Biventriculare with Ventricular Septal Defect: Prenatal Diagnosis
}

\author{
${ }^{1}$ Ravi Nirmalkumar Rajdeo, ${ }^{2}$ Kishor Taori, ${ }^{3}$ Jawahar Rathod, ${ }^{4}$ Nekee Navin Sejpal
}

\section{ABSTRACT}

Cor triloculare biventriculare is a very rare congenital cardiac anomaly in which there is complete absence of interatrial septum resulting in three-chambered heart. It can be associated with various other congenital abnormalities like ventricular septal defect, polysplenia, Ellis-van creveld syndrome or persistent left-sided superior vena cava. Here we report a case of antenatal diagnosis common atrium and ventricular septal defect in a fetus of average gestational age of 29 weeks in a primigravida.

Keywords: Cor triloculare biventriculare, Ventricular septal defect, Common atriu.

How to cite this article: Rajdeo RN, TaoriK, Rathod J, Sejpal NN. Cor Triloculare Biventriculare with Ventricular Septal Defect: Prenatal Diagnosis. Int J Infertil Fetal Med 2015;6(1):40-42.

Source of support: Nil

Conflict of interest: None

Date of Received: 25-01-15

Date of Acceptance: 18-03-15

Date of Publication: April 2015

\section{INTRODUCTION}

Cor triloculare biventriculare is a rare congenital cardiac anomaly in which there is complete absence of interatrial septum and resultant single large atrial chamber with both pulmonary veins and superior vena cava draining into the common chamber. Great vessels are usually normally oriented arising from aorta from the left and pulmonary trunk from the right ventricle.

Single atrial chamber presents similar to a large ASD with hypoxemia and cyanosis in postnatal period. We describe a case of antenatal diagnosis of Cor triloculare biventriculare with VSD in a primigravida.

\footnotetext{
${ }^{1}$ Resident Doctor, ${ }^{2}$ Professor and Head

${ }^{3}$ Assistant Professor, ${ }^{4}$ Resident Doctor

${ }^{1-3}$ Department of Radiodiagnosis, Government Medical College Nagpur, Maharashtra, India

${ }^{4}$ Department of Anesthesia, BJ Medical College, Pune Maharashtra, India

Corresponding Author: Ravi Nirmalkumar Rajdeo, Resident Doctor, Department of Radiodiagnosis, Government Medical College, Nagpur, Maharashtra, India, Phone: 8275331366 e-mail: ravi_iggmc@yahoo.co.in
}

\section{CASE REPORT}

A 24-year-old pregnant G1P0L0 lady married for 2 years visited the outpatient department of our hospital for routine antenatal evaluation. It was a nonconsanguineous marriage. This was her first antenatal visit, advised to do antenatal anomaly scan and other antenatal investigation. Patient was taking iron and calcium tablets. No significant past history. No history of X-ray irradiation. No history of congenital anomalies in the family. She is a housewife, husband is an office clerk. No history of diabetes in mother.

Antenatal ultrasound was performed on Philips HD 11 XE ultrasound machine; Fetal echocardiography revealed a single atrial chamber with complete absence of the interatrial septum (Fig. 1) Great vessels appears normally orientated (Fig. 2). There was a defect noted in the ventricular septum in the mid part. SVC and IVC were normally oriented. Aorta appears normal in caliber and show normal color flow and Doppler waveform. Amniotic fluid index was normal for gestational age.

Patient was further investigated with a fetal MRI on 1.5 T Philips MRI machine with T1W and T2W sequences in sagittal, axial and coronal planes. Ultrasound findings were confirmed showing situs solitus, single large atrial chamber (Fig. 3) with VSD, complete evaluation of abdominal viscera, brain, spinal cord and skeletal system revealed normal morphology and orientation.

Parents were counseled regarding the condition, its prognosis and its syndromic association. Single live small for gestational age baby was delivered as parents opted for termination. The oxygen saturation was unsatisfactory and fluctuating with mean value of $88 \%$. Baby was admitted to NICU at Government Medical College, Nagpur. Postnatal echocardiography was performed which revealed situs solitus, normally oriented great vessels and single large atrial chamber receiving the drainage from both vena cava and pulmonary veins (Fig. 4). There was a large defect noted in the mid part of the interventricular septum resulting in an additional left to right shunt (Fig. 4). The abdominal viscera appeared normal in morphology and orientation on postnatal sonography. 


\section{DISCUSSION}

Single common atrial chamber is a rare congenital cardiac anomaly which many of the times associated with simultaneous other congenital malformations like VSD, left sided SVC, polysplenia, isolated dextrocardia. ${ }^{1}$ Campbell and Nissen classified the rare anomaly into three different groups: persistent ostium primum, a partial AV canal and a complete AV canal defect. ${ }^{2}$ Levy et al recommended the term 'single atrium' for a condition with complete absence of atrial septum in absence of malformations of AV valves, and absence of any interventricular communication. The term 'common atrium' is used for a condition with complete absence of atrial septum accompanied by malformations of AV valves, with or without interventricular communication as in our case. ${ }^{3}$ Complete absence of the atrial septum may exist alone and unassociated with malformations of $\mathrm{AV}$

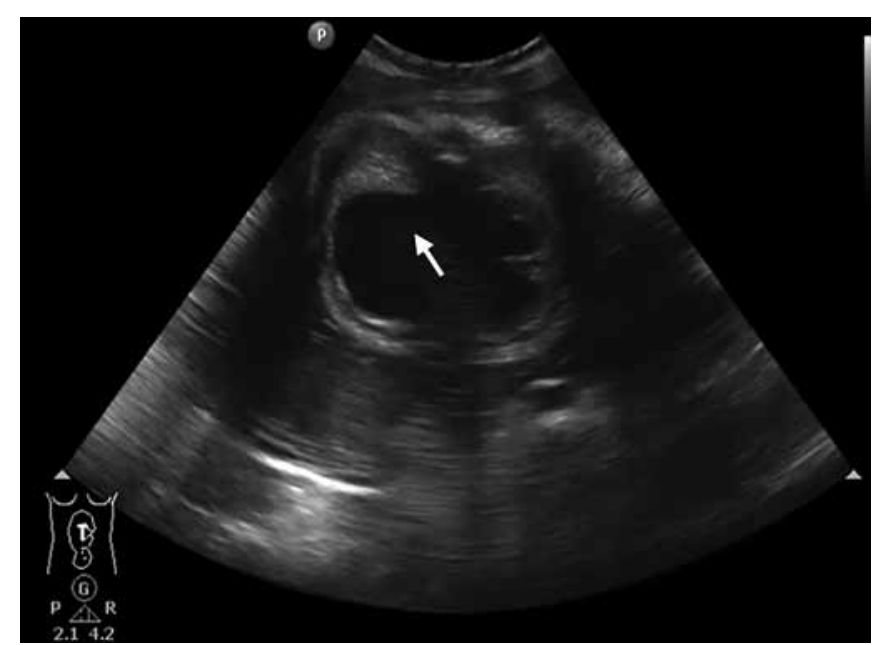

Fig. 1: Four chambered view in fetal echocardiography showing complete absence of interatrial septum with defect in the interventricular septum (arrow)

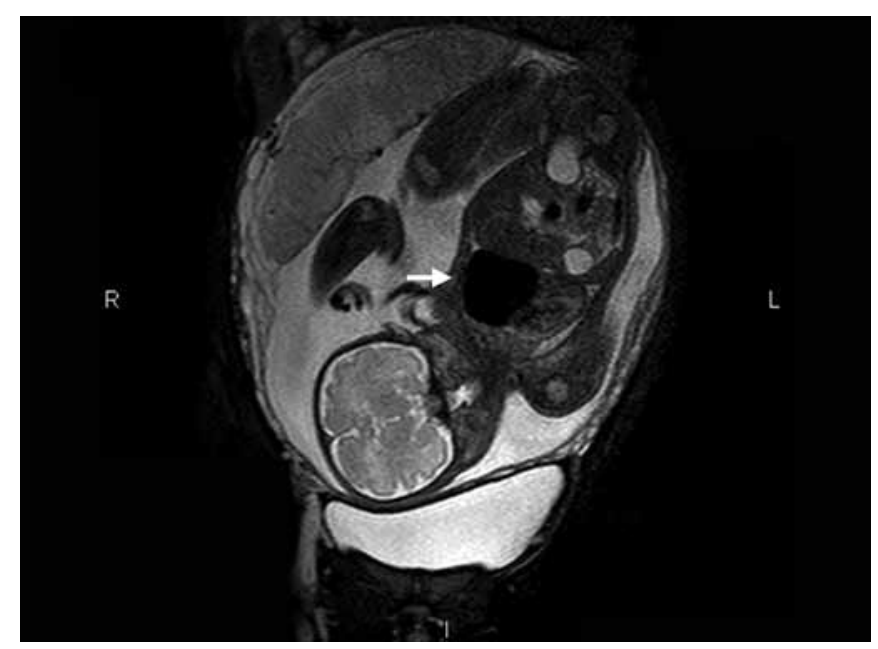

Fig. 3: Fetal magnetic resonance imaging showing common atrial chamber (block arrow) valves as stated by Lewis et al. ${ }^{4}$ Supporting evidences were provided by Munoz-Armas et $\mathrm{al}^{5}$ the association of the condition with various anomalies has been studied, 14 cases of common atrium with persistent AV canal have been reported by Hung J-S et al. ${ }^{6}$ Ellis et al $^{7}$ reported 5 cases of common atrium, and he considered that a complete absence of atrial septum is always associated with $\mathrm{AV}$ valve anomalies. However, no valvular abnormalities were observed in our case. There is single report from $\mathrm{Lu} \mathrm{C}-\mathrm{W}$ et $\mathrm{al}^{8}$ who reported common atrium with common AV valve and ventricular defect in association with Holt-Oram syndrome.

Normal interatrial septum formation occurs between 4thand5thweek of intrauterinelife. Growtharrest of septum primum and secundum results in an absence of atrial septum. ${ }^{9}$ Dexter $^{10}$ showed that an atrial septal defect of more than $2 \mathrm{sq} \mathrm{cm}$. cross-sectional area resulted

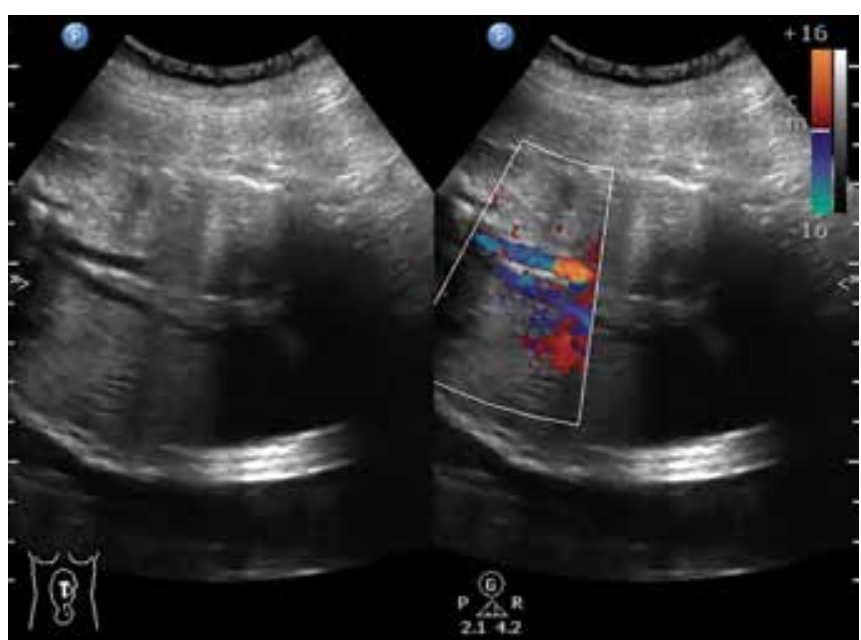

Fig. 2: Normally oriented great vessels. Inferior ven cava opening into the common atrial chamber

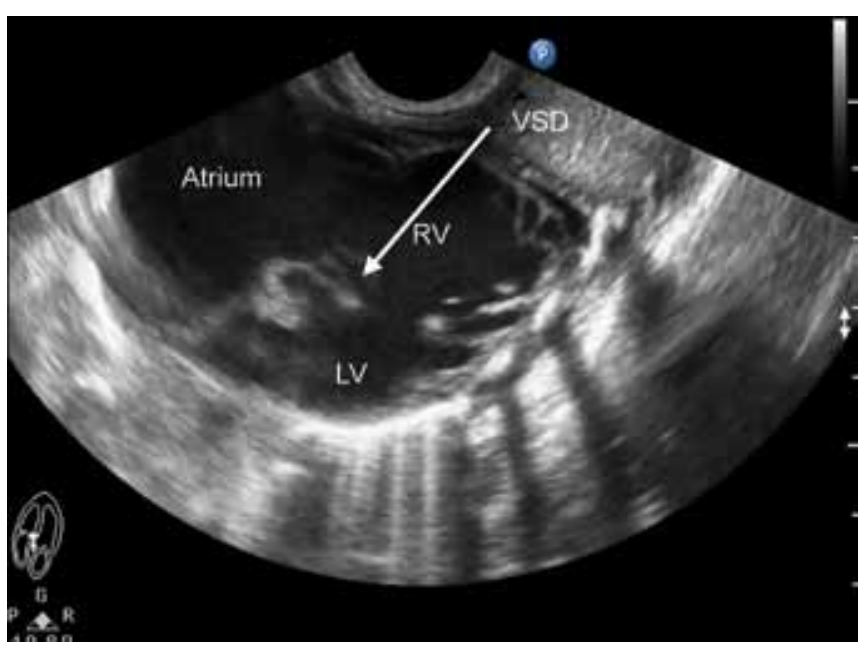

Fig. 4: Postnatal echocardiography for chambered view showing absence of interatrial septum with ventricular septal defect (white arrow) 
in diminution or abolition of the normal atrial pressure difference between the two atria, thus producing a physiologically common atrium. Shaher and Johnson ${ }^{11}$ found that the hemodynamics of common atrium are similar to those of a large atrial septal defect.

\section{PROGNOSIS}

Prognosis and survival of patients with complete absence of interatrial septum varies according associated cardiac anomalies. In an analysis by Abbott ${ }^{12}$ of thousand cases of congenital heart disease only 5 patients with this malformation were identified. The average age at death was 6 years and the maximum age of survival was 31 years. Brown ${ }^{13}$ gives several references to isolated case reports but few of these cases survived beyond middle age. To the best of our knowledge no significant study reports the recurrence rate of complete absence of interatrial septum in subsequent pregnancies, due to very low incidence of the condition. The anomaly is considered rarer than complete absence of interventricular septum the incidence of which is 0.05 to $0.1 / 10000$ live-births. ${ }^{15}$ There is no associated maternal high risk condition has been documented.

The anomaly predisposes the infant to variety of complications, such as premature death, septic embolism, heart failure, ventricular dysfunction, mitral and tricuspid regurgitation, systemic hypertension and conduction abnormalities. $^{14}$

\section{COUNSELING}

Parents should be counseled regarding the incidence of anomaly, its syndromic associations, prognosis, recurrence rate and treatment options. They should also be advised to seek early prenatal diagnostic tests for congenital heart disease in subsequent pregnancies like fetal echocardiography, prenatal maternal serum screening, chorionic villous sampling and amniocentesis.

\section{REFERENCES}

1. Sangam MR, Devi SS, Krupadanam K, Anasuya K. Cor triloculare biventriculare with left superior vena cava. Folia Morphol 2011;70(2):135-138.

2. Campbell M, Nissen GA. Endocardial cushion defects, common atrioventricular canal and ostium primum. Br Heart J 1957 Jul;19(3):403-418.

3. Levy MJ, Salomon J, Vidne BA. Correction of single and common atrium, with reference to simplified terminology. Chest 1974;66(4):444-446.

4. Lewis FJ, Winchell P, Bashour FA. Open repair of atrial septal defect: results in sixty-three patients. JAMA 1957;165(8):922-927.

5. Munoz-Armas S, Gorrin JR, Anselmi G, Hernandez PB, Anselmi A. Single atrium. Embryologic, anatomic, electro cardiographic and other diagnostic features. Am J Cardiol 1968;21(5):639-652.

6. Hung J-S, Ritter DG, Feldt RH, Kincaid OW. Electrocardiographic and angiographic features of common atrium. Chest 1973;63(6):970-975.

7. Ellis FH Jr, Kirklin JW, Swan HJC, Dushane JW, Edwards JE. Diagnosis and surgical treatment of common atrium (cor triloculare-biventriculare). Surgery 1959;45(1):160-172.

8. Lu C-W, Ou T-Y, Hua Y-M, Ho T-Y, Hsu M-L. Unusual cardiac malformation in Holt-Oram syndrome. J Med Sci 2002;22: 139-142.

9. Rojas CA, El-Sherief A, Medina HM, Chung JH, Choy G, Ghoshhajra BB, Abbara S. Embryology and development defects of the interatrial septum. AJR Am J Roentgenol 2010 Nov;195(5):1100-1104.

10. Dexter L. Atrial septal defect. Brit Heart J 1956;18(2):209-225.

11. Shaher RM, Johnson AM. The hemodynamics of common atrium. Guy's Hosp Rep 1963;112:166.

12. Abbott ME. Atlas of congenital cardiac disease. American Heart Association, New York 1936.

13. Brown JW. Congenital heart disease. 2nd ed. Staples Press, London 1950.

14. Raj V, Joshi S, Ho Y-C, Kilner PJ. Completely unroofed coronary sinus with a LSVC draining into LA studied by cardiovascular magnetic resonance. Intern J Radiol Imag 2010;20(3):215-217.

15. Nabati M, Bagheri B, Habibi V. Coincidence of total anomalous pulmonary venous drainage to the superior vena cava, common atrium and single ventricle: a very rare condition. Echocardiography 2013;30(4):E98-101. 